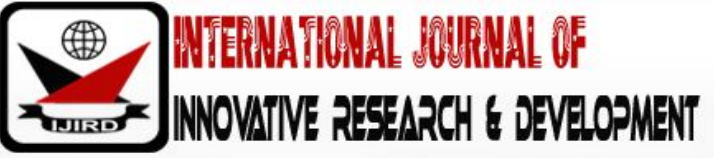

ISSN 2278 - 0211 (Online)

\section{Investigating the Effectiveness of Motivational Interviewing on the Academic Performance of Senior Secondary Students in Private Schools in Niger State, Nigeria}

\author{
Adaeze Chike-Okoli \\ Senior Lecturer, Department of Educational Administration \& Planning, National Open University of \\ Nigeria, Nigeria \\ Tochukwu Okoli \\ Postgraduate Student, Hillcrest International School Minna, Niger State, Nigeria
}

\begin{abstract}
:
Large numbers of students in spite of having normal intelligence level have an inadequate academic motivation and do not show a good academic performance in different levels of education. The unmotivated students in classroom interaction with the teacher could be responsible for the observed poor performance of students and the widely acclaimed fallen standard of education in Nigeria. This study was designed to determine the effectiveness of motivational interview in promoting motivation among students in private secondary schools. It was aimed at answering the question: Does motivational interview have significant influence on academic performance of senior secondary SS 2 students in private schools? The study adopted the pretest-posttest experimental group design-two levels of independent variables (experimental groups and a control) and two levels of gender (male and female). The experimental group participants are given the MI intervention, while the control group participants received no intervention. A purposeful sampling procedure was adopted to obtain 120 participants from the two (2) sample secondary schools. Data were collected by employing English language Achievement Test (ELAT), Motivation strategies for Learning Questionnaire (MSLQ) and the Brief Academic Motivational Instrument (BAMI) as well as classroom observations. Both pretest and posttest scores were analyzed using the descriptive and t-test statistical analysis to test the hypotheses. Evidently, the experimental group that was exposed to motivational interviewing performed better than the control group that was exposed to traditional teaching method. This implied that with motivational interviewing combined with conventional teaching methods students performed with higher scores than when taught with conventional teaching method only. It is recommended that secondary school teachers should be trained on the effective use of motivational interview, MI skills and strategies for instruction through seminars, workshops and conferences.
\end{abstract}

Keywords: Effectiveness, motivational interviewing, academic performance, and private secondary schools

\section{Introduction}

When the issue of Nigeria educational system today is raised the first set of thoughts that comes to mind are; decline in standard, deterioration of facilities, examination malpractices, mass promotion syndrome and the like before any other thing else (Odia and Omofonwan, 2007). However, the issue of declining academic performance of students in Nigeria secondary schools has generated much interest among stakeholders in the education sector in Niger State (Omotere, 2013). The quality of education and performance of students depend on the teachers as reflected in the discharge of their duties. Over time pupils' academic performance in both internal and external examinations had been used to determine the effectiveness of teachers and teaching (Ajao, 2001; Agharuwhe, 2013). This was buttressed by Ogunsaju (2014) that the academic standard of students in all Nigerian educational institutions has fallen considerably below societal expectations.

Teachers have been known to have important influence on students' academic achievement and they also play a crucial role in educational attainment because the teacher is ultimately responsible for translating educational policies ad principles into actions based on practice during interaction with the students (Afe, 2001; Agharuwhe, 2013). Both teaching and learning depend on teachers; no wonder an effective teacher has been conceptualized as one who produces desired results in the course of his duty as a teacher (Uchefuna, 2001; Chike-Okoli, 2006). However, in spite of the position of the teacher in the classroom teaching and learning situation, school counselors identified underachieving students as one of the most challenging to work with because these students are capable of succeeding academically, but are unmotivated (Butler, 
2009). Educators and researchers have been examining the contributing factors or methods of increasing motivation (Bleuer, 1987).

Large numbers of students in spite of having normal intelligence level have an inadequate academic motivation and do not show a good academic performance in different levels of education (Bowman, 2007). Poor study habits, difficulties in accepting friends, low concentration, disciplinary problems at school and home environment are the behavior patterns that have allocated the low self-academic status students and also have proposed the low self-confidence, lack of direction in target, low responsibility, ambivalent, emotional immaturity and lower mental health (Covington and Mueller, 2001). These problems affect active engagement of students in school. Active engagement in school is critical to a student's academic success; students with higher engagement are better adjusted to school and achieve higher academic grades. Consequent upon the observed deterioration in the academic achievement, attitude and values of secondary school students in public secondary schools, one wonders if the high failure rates and the failure of the students especially if external examination is not a reflection of the readiness level of the student.

Therefore, the unmotivated students in classroom interaction with the teacher could be responsible for the observed poor performance of students and the widely acclaimed fallen standard of education in Nigeria. Indeed, low-academic achievement status students achieve a level of performance that is lower than their abilities and potentials (Mojtaba et al, 2015).

This study was designed to determine the effectiveness of motivational interview in promoting motivation among students in private secondary schools. It was aimed at answering the question: Does motivational interview have significant influence on academic performance of senior secondary SS 2students in private schools?

Different interventional methods have been proposed. Traditional instructional methods have been given insufficient opportunities for students to construct their own learning. Large class size made it difficult to address the specific needs of individual learners. Omotere (2013) in his study of the ideal class size and its effects on effective teaching and learning in Ghana concluded that class sizes above 40 have negative effects on students' achievement. Adegoke (2011) reports that many of these students are poorly motivated and find classroom experience frustratingly difficulty. In order to be motivated to learn in any discipline, students must participate in activities that are personally meaningful and worthwhile. Evidently, poor motivation leads to low achievement (Glynn et al, 2009). Eliciting students' individual capabilities, intelligence and creative thinking can only be achieved through student centered instructional methods (Adegoke, 2011).

Adolescents who have reported higher levels of motivation have higher scores on standardized tests and improved work production (Alfaro, Umana-Taylor, Gonzales-Backen, Bamaca \& Zeickers, 2009). In addition, academically motivated students engage in their school work with confidence and interest, are less likely to leave school in view of graduation, suffer fewer disciplinary problems, and are increasingly resilient in the face of setbacks (Pajares \& Urdan, 2002). It can be hypothesized that the discrepancy between ability and work production may be explained by lack of motivation to engage in learning (Wigfield, Lutz \& Wagner, 2005). In a study examining a student population of 13,300 ranging in age from 12-16 drop-outs, $10 \%$ of the students were strongly unmotivated with no socio-emotional difficulties and average grades (Janoz, Archambault, Monzot \& Pagani, 2008).

Recently, an interventional approach has been proposed as a motivational interview that can be effective and efficient for enhancing positive behavioral change that can result to higher performance (Butler, 2009, Broody, 2009, Adams \& Madison, 2006; Miller \& Rollnick, 2002). Motivational interview is a client-centered approach to behavior change. Here, the expert practitioner is familiar with clients' uncertainty and readiness to change and is able to exploit techniques and strategies that are responsive to the client (Ferla, Valcke and Cai, 2009).

Motivational interview is guidance oriented. The goal is guidance of client in order to develop his/her goals and current behaviors (Diallo and Weiss, 2009). The main goal of motivational interview is reviewing and solving the ambivalent and on the other hand, solving the disparity and revealing it. Based on the method of interventional of motivational interview (unless the ambivalent be uncovered and the person be unable to solve it) change occurs hardly (Mojtaba et al, 2015)

Motivational interview could be used to engage students and transform classroom instruction into a series of rich memorable experiences and therefore reduce boredom and forgetfulness. The MI theory takes into account Prochaska and DiClementes's (1982) transtheoretical model of change, and tries to help the client to prepare for change during the sessions. The model of change describes change as a process that evolves through several stages. MI bases itself on identified 2 phases of five central processes of change: (1) the pre-commitment phase - (a) the pre-contemplation stage, (b) the contemplation stage and (c) the preparation stage. Behavioral change starts in phase 2: the post-commitment phase, with (d) the action stage and behavior is sustained at (e) the maintenance stage (Conrado, 2015; Mojtaba et al., 2015).

Motivational Interviewing (MI), a client-centered, therapeutic technique, developed for use in the addictions fields, however, may also have efficacy in the academic arena (Miller \& Rollnick, 2002), motivational interviewing builds a collaborative relationship between a counselor and the client, and illuminates discrepancy between the client's values, goals and behaviors (Miller \& Rollnick, 2002).

Research has demonstrated that MI improves the academic performance of college students with low academic progress (Daughterty, 2008) and suggests that MI is likely to be an effective intervention for younger students with school motivation issues (Kittles \& Atkinson, 2009; Scheel \& Gonzalez, 2007; McNamara, 1992). Nevertheless, at this time there is need for additional research with quantitative findings on the impact of MI in educational settings (Kittles \& Atkinson, 2009; Atkinson \& Woods, 2003; Otwell \& Mullis, 1997). 
Motivational interview is a particular kind of conversation about change therapy, consultation and method of communication (Ferla, Valcke and Cai, 2009). Motivational interview provides interactive learning environment and is designed to provide unique method to teach, reinforce and apply information. It provides immediate/ constant feedback, allows simultaneous observation of ambivalence and offers a flexible environment that enables students to proceed on their own pace and also become active learners (Chike-Okoli, 2018; Jensen, 2011). Motivational interview has been showing its effectiveness in the school environments and in improving and promoting the status of low achievement adolescents that are suffering from depression (Broody, 2009; Chike-Okoli et al., 2018), prevention of obesity in girls (Flattum et al, 2009) and tobacco consumption and drug abuse (Lawen dowski, 1998).

With four principles of motivational interview (empathy, revealing disparity, deal with resistance and support selfefficacy) and due to the wide range of motivational interview applications and the potential that it has in the field of education for application, literature evidence in Chike-Okoli et al, (2018) revealed the effectiveness of motivational interview over the traditional method in classroom setting across different disciplines at secondary levels in Nigeria. It seems that its consultative style is an appropriate technique in order to help adolescents.

Declines in academic motivation and student success have been widely observed in Nigeria (Chike-Okoli, 2018). Academic success is dependent on motivation (Klose, 2008), motivation is one of the states that drives and sustains learning behavior. Researchers have identified intrinsic and extrinsic motivation, goal orientation, task value, self-determination, and self-efficacy and assessment anxiety as important construct for learning (Glynn \& Koballa, 2006; Glynn et al, 2009).

\section{Statement of the Problem}

Research shows that one of the main factors causing students to withdraw from schooling in view of high school completion is lack of motivation (Cordor, 1999). There is a concern regarding the level of underachievement by students, with lack of work production and grades as indicators of underachievement (Chukwu-Etu, 2009). Dropping out of school is a significant problem that has serious personal and societal repercussions (school, Madabhushi \& Backhaus, 2009). Motivation is a factor associated with school success. Achievement can be understood in terms of academic motivation.

While successful school counseling programs must include academic interventions (Otwell \& Mullis, 1997; Walz \& Bleuer, 1997), research has repeatedly demonstrated that academic progress is dependent upon motivation and motivation intervention has been identified as the primary issue in counseling for many students (Klose, 2008).

Underachievement can lead to students distancing themselves from the significant adults in their life (Bleuer \& Walz, 2002). In addition, low-self-esteem and school becoming a difficult place to be, only serves to reinforce feelings of failure (Bleuer, 1987). These experiences of failure can be emotionally destructive for a student and can lead to learned helplessness and feelings of inability which negatively impacts future life success (Bempechat, Boulay; Piergross \& Wenk, 2008). Given this information, determining why these students are academically underachieving is of critical importance. Therefore, the main goals for school administrators are to discuss and enhance motivation for change (Tevijaw \& Monti, 2004); however, determining the most impactful intervention is still necessary.

Motivational interviewing appears to be a good technique to use with adolescents because of its brief duration, nonconfrontational, and empathetic counseling style (Lawendowski, 1998; Tevjaw \& Monti, 2004) in addition, MI focuses on learning skills to modify or regulate behavior (Kittles \& Atkinson, 2009). It is evident from literature that motivational interviewing is an effective intervention to enhancing the academic performance of low achievement status students. However, there is paucity of information on the effect of Motivational Interview on the higher achievement status secondary school students. This study aims at investigating the effectiveness of motivational interviewing on senior secondary SS2 students in Private schools in Niger state.

\subsection{Research Questions}

The study is guided by the following research questions:

- What are the differences in the achievement of private SS2 students taught using motivational interviewing instructional approach and conventional method of teaching?

- Is there any difference in the mean achievement scores of male and female private SS2 students exposed to motivational interviewing instructional approach?

\subsection{Research Hypotheses}

The following null hypotheses were formulated and tested at the 0.05 level of significance:

- There is no significant difference in the performance of private SS2 students taught English language using motivational interviewing instructional approach and conventional teaching method

- There is no significant difference in the mean achievement scores of male and female private SS2 students exposed to motivational interviewing instructional approach.

\section{Methodology}

This study applied quantitative research methods. 


\subsection{Study Design}

It adopted the pretest-posttest experimental group design-two levels of independent variables (experimental groups and a control) and two levels of gender (male and female). The Experimental Group was taught selected concepts of English language using motivational interviewing instructional approach (MIIA), whereas the control group was taught using the conventional teaching method (CTM). The independent variables in this study are teaching methods. These are (I) motivational interviewing and (ii) conventional teaching method. The dependent variable is the post-test performance of the students in the two groups. The moderating variable is gender of students in the study. The experimental group participants are given the MI intervention, while the control group participants received no intervention. Comparisons of the academic performance of the students were drawn by comparing the responses of the participants in the two groups.

\subsection{Sample and Sampling Technique}

Multi-stage sampling techniques were adopted for the purpose of the study. A purposeful sampling procedure was adopted to obtain the two (2) sample secondary schools in Minna metropolis of Niger State, Nigeria. The two schools were randomly assigned to Experimental Group and Control Group respectively. Stratified sampling technique was used to select the SS2 students. The sample consisted of 120 participants of whom $60(50 \%)$ each were randomly assigned to the MI intervention group and non-intervention control group respectively. 15 males (25\%) and 15 females (25\%) were purposely selected from the experimental group to test gender effect. The participants ages ranged between 14 to 22 years (mean age).

All students completed the self-efficacy and Academic Motivation - revised scales as pretests. Five days after the intervention was administered with the Experimental group participants, a summary was sent to the students through (4) teacher -research -assistants so the participants could refer back to the interview content. Fourteen (14) days after the pretest was administered, a follow up message for the posttest was sent to the students, and the students completed the posttest using the Motivation Strategies for Learning Questionnaire (MSLQ). Questions in the post-test were the same like those used in the pre-test; however, questions in the pre-tests assessed the experimental groups' and the control groups' prior knowledge of the chosen English Language concepts while the MSLQ assessed their motivation toward English Language learning. The classroom observations were also carried out in order to determine non-verbal responses during the lessons.

\subsection{Research Instruments}

Data were collected by employing English language Achievement Test (ELAT), Motivation strategies for Learning Questionnaire (MSLQ) and the Brief Academic Motivational Instrument (BAMI) as well as classroom observations. Both ELAT and MSLQ were administered as a pre-test and subsequently as a post-test.

\subsubsection{English Language Achievement Test (ELAT)}

The English Language Achievement Test (ELAT) consist of 50 multiple choice objective items with five options (A-E) adopted from past examinations of West African Examination Council (WAEC) May/June 2011-2016) and National Examination Council (NECO, June/July, 2011-2016). The appropriateness of the options provided for each item was established by four (4) subject teachers, and test and measurement experts, their suggestions were incorporated in the final draft. To test the reliability, the ELAT was piloted to 50 students outside the sample. The reliability coefficient was 0.89 and considered acceptable.

\subsubsection{The Motivation Strategies for Learning Questionnaire (MSLQ)}

The MSLQ is a self-report scale developed by Pintrich et al, (1991), and was developed from a social-cognitive theoretical perspective, which consisted of two primary categorized scales: the motivation scale and learning strategies scale. The self-efficacy for learning and performance has eight items () and is measured with a 7-point Likert scale of 1 (not at all true of me) to 7 (very true of me). The greater the accumulated score, the higher the academic self-efficacy the participant demonstrates.

\subsubsection{The Brief Academic Motivational Instrument (BAMI)}

The Brief Academic Motivational Instrument (BAMI) was used as a Motivational Interviewing (MI) tool to enhance the academic motivation and academic self-efficacy of students. It is a brief intervention to improve students' motivation to study. Through the BAMI, the investigator hopes to encourage students to reflect on their study choices, find solutions to change, consider possible obstacles they may encounter and solutions to remove those obstacles.

The Brief Academic Motivational Instrument (BAMI) was adapted for this study from the self-Administrated Motivational Instrument (SAMI) (Duffy \& Rimmer, 2008). It allowed students to evaluate their current investigation habit and elaborate on the advantages and disadvantages of remaining their current status quo and improving it.

The instrument comprised of four (4) sections, which included; (1) Rating of the students' perceived current and potential academic performance on a Likert scale of O (not very well) to 9 (very well) and reflection of the difference between the ratings of the two scores (2) identifying their problems with studying, evaluating the advantages of maintaining the status quo, and of changing their study approach, (3)Evaluating obstacle(s) in making changes, generating possible solution(s) (4) Elaborate what they would anticipate as their accomplishment, if they succeed in the plan. The Brief Academic Motivational 
Instrument (BAMI) was administered to the experimental group as a semi-structured interview to the participants and was completed within 20-30 minutes depending on the participant.

\subsection{Data Analysis Technique} hypotheses.

Both pretest and posttest scores were analyzed using the descriptive and t-test statistical analysis to test the

\section{Results}

4.1. Pretest Mean Scores of Students Assigned to Experimental and Control Conditions

\begin{tabular}{|c|c|c|c|c|c|c|c|}
\hline Variables & $\mathbf{N}$ & $\mathbf{D f}$ & $\underline{\mathbf{X}}$ & SD & t-Value Calculated & t-value Critical & Remark \\
\hline Experimental & 60 & & 18.93 & 7.29 & 0.20 & 1.65 & NS \\
\hline Control & 60 & 118 & 19.20 & 7.12 & & & \\
\hline
\end{tabular}

Table 1: T-test Comparison of the Mean Scores of Experimental and Control Groups on Pretest

$$
\text { NS }=\text { Not Significant at } P=.05
$$

Table 1 shows the result of pretest for experimental and control groups. The mean pretest score is 19.20. The mean difference is 0.027 , $t$-value calculated is 0.20 less than $\mathrm{t}$-value critical of 1.65 ( $\mathrm{tcr}=1.65 \mathrm{df}=118, \mathrm{P}<.05$ ). This shows that there is no significant difference between the two groups at 0.05 level of significance Results show that the two groups are homogenous and comparable, suitable to take part in the study.

- Hypothesis 1: There is no significant difference in the mean achievement scores of students taught concept in English Language with motivational interviewing instructional approach and those taught with conventional teaching method.

\begin{tabular}{|c|c|c|c|c|c|c|c|}
\hline Variables & $\mathbf{N}$ & $\mathbf{D f}$ & $\underline{\mathbf{X}}$ & SD & t-value Calculated & t-Value Critical & Remark \\
\hline Experimental & 60 & & 71.13 & 7.86 & 17.85 & 1.65 & $\mathrm{~S}$ \\
\hline Control & 60 & 118 & 48.30 & 6.04 & & & \\
\hline
\end{tabular}

Table 2 T-test Comparison of the Posttest Means Achievement Scores of

Experimental and Control Groups

Significant at $\mathrm{P}=.05$

Table 2 shows the result of the posttest mean scores for experimental and control groups. The mean posttest scores for experimental group are 71.13 while that of the control group is 48.30. The t-test calculated of 17.85 shows that there is a significant difference between the experimental and control groups at the .05 significant level $(\mathrm{tcal}=17.85, \mathrm{df}=118, \mathrm{P}<05$ ). Therefore, hypothesis 2 is rejected. In other words, there was a significant difference in the mean achievement scores of students taught concept in English language with motivational interviewing and conventional teaching method

- Hypothesis 2: There is no significant difference in the mean achievement scores of male and female (experimental) groups.

\begin{tabular}{|c|c|c|c|c|c|c|c|}
\hline Variables & $\mathbf{N}$ & $\mathbf{D f}$ & $\underline{\mathbf{X}}$ & SD & $\begin{array}{c}\text { t-value } \\
\text { Calculated }\end{array}$ & $\begin{array}{c}\text { t-value } \\
\text { Critical }\end{array}$ & Remark \\
\hline $\begin{array}{c}\text { Male } \\
\text { (Experimental) }\end{array}$ & 15 & & 63.87 & 4.37 & & & NS \\
\hline $\begin{array}{c}\text { Female } \\
\text { Experimental }\end{array}$ & 15 & 28 & 65.47 & 4.93 & 0.94 & 1.70 & \\
\hline
\end{tabular}

Table 3: T-test Comparison of the Post-Test Means Achievement Scores of Male and

Female Experimental Groups in Sample Secondary Schools

$$
\text { NS }=\text { Not Significant at } \mathrm{P}=.05
$$

The post-test mean achievement scores for male participants is 63.87 while that of the female is 65.47 . The t-value calculated of 0.94 was less than the t-value critical of 1.70 . This implies that there is no significant difference in the mean achievement scores of male and female experimental groups in the sample secondary schools.

Thus, no gender disparity is exhibited in the learning of English Language using motivational interviewing instructional approach. This result is in consonance with the findings of Mojtaba et al (2015) that showed that the scores of self-efficacy and self-concept of subjects had a significant increase after motivational interviewing but showed no gender difference. This implies that male students' achievement did not differ significantly from that of their female counterparts when both were taught using motivational interviewing as an intervention. 


\section{Findings and Discussion}

Evidently, the experimental group that was exposed to motivational interviewing performed better than the control group that was exposed to traditional teaching method. This implied that with motivational interviewing combined with conventional teaching methods students performed with higher scores than when taught with conventional teaching method only. It could be said that motivational interviewing approach as a teaching method enhanced learning of English language by secondary school students.

The result agrees with the findings of strait et al, (2012) which used MI as a counseling technique in a randomized experiment with the aim of improving academic achievement of middle school students. The results showed that in comparison with the treatment and control group, the treatment group showed a significant improvement in Language Arts and Reading (Strait et al; 2012).

The study reflects the benefit of MI as a brief intervention. The use of motivational interview allows students to classify their goals and strengthen its own values and this can act as a capital in process of changing for their behavior and lead them to become successful students and play their contribution in society (Butler, 2009).

Mojtaba et al (2015) reports that motivation interview can be effective for growing adolescents because it is not aggressive and provocative. Changes that occur in adolescence have proportion with principles of motivational interview (empathy, revealing disparity, deal with resistance and support of self-efficacy (Miller \& Rollnick, 2002). The result also concurs with the findings of Chike-Okoli et al, 2018 which investigated the effectiveness of motivational interview on the academic performance of low-achievement status students.

Chike-Okoli et al, (2018) reports that the high level of performance of students exposed to motivational interviewing over those taught using conventional classroom teaching method established that using Motivational Interviewing teaching skills was a better approach for teaching secondary school students in Nigeria

\section{Conclusion}

The aim of this study was to investigate whether the use of motivational interviewing instructional approach would significantly enhance the learning of English Language concepts in SS2 students in private secondary schools, and among male and female students as measured by the English Language Achievement Test. The result of this study confirms that motivational interview is effective in improving and promoting academic performance of adolescents in secondary schools. This agrees with the overview study of Madson et al (2009) about 28 published articles from 1999 to 2007, have shown the ability of motivational interview in improving the development of study skills and self-efficacy.

Research has shown that MI is an effective intervention for addiction and other health related behaviors (Heather, 2011). By applying these skills and strategies with the academically unmotivated adolescent population, school counselors can intervene to create positive behavior change and also encourage other students to even higher performance.

Mojtaba et al, 2015 observed that adolescents often are not comfortable with therapy techniques which have nature of cognitive because they are in developing of cognitive skills and self-express is not easy for them. Motivation interview is not aggressive and provocative. According to Madson et al, some of researchers believe that when motivational interview is added to other interventional methods, it leads to leave a significant effect.

School counselors often in working with adolescents in order to find the ways of connection with these students and motivating them to change in their lives for better and positive choice are facing some challenges Mojtaba et al, 2015). The motivational interview differs somewhat from therapy and consultation concepts.

\section{Recommendation}

Counselor is not a source of power in motivational interview, but more in a friendly meeting and discovering the cause of problems, deals with resistance, specify the discrepancy between values and objectives with current behavior, understanding the contradictions and ambivalent and familiarity with six stages of change are sources of power. Motivational interview should be used to increase students' motivation and enhance their active participation.

It is recommended that secondary school teachers should be trained on the effective use of motivational interview, MI skills and strategies for instruction through seminars, workshops and conferences.

School counselors should engage in data driven activities that promote academic success of students.

\section{References}

i. Adams, B. J., \& Madson, B. M. (2006). Reflection and outlook for the future of addictions treatment and training: an interview with William R. Miller. Journal of Teaching in the Addictions, 5(1), 95-109.

ii. Afe J.O. (2001). Reflections on Becoming a Teacher and Challenges of Teacher Education. Inaugural Lecture Series. 64. University of Benin, Benin City: Nigeria.

iii. Agharuwha, A. Akiri (2013). Effect of Teachers' Effectiveness on Students' Academic Performance in Public Secondary Schools; Delta State-Nigeria. Journal of Educational and Social Research MCSER publishing vol 3(3) pp105-111

iv. Ajao, W. (2001). Cadbury is determined to move Education Forward. Vanguard, December 27 2001, P. 16

v. Alfaro, C.E., Umana-Taylor, A.J., Gonzales-Backen, M.A., Bamaca, M., \& Zeiders, Z.H. (2009). Latino adolescents' academic success: the role of discrimination, academic motivation, and gender. Journal of Adolescence, 32, 941-962. 
vi. Atkinson, C., \& Woods, K. (2003). Motivational interviewing strategies for disaffected secondary school students: a case example. Educational Psychology in Practice, 19(1), 49-64.

vii. Bleuer, J. (1987). Counseling underachievers: a counselors' guide to helping students improve their academic performance. Ann Arbor, Michigan: ERIC Counseling and personnel Services Clearinghouse. (ERIC Document Reproduction Service No. ED286112)

viii. Brody, A. (2009). Motivational interviewing with a depressed adolescent. Journal of Clinical Psychology, 65(11), 11681179.

ix. Bowman, R. (2007) how can students be motivated: A misplaced question? Cleaning House, 81, 81-86. Retrieved June 16, 2008, from Eric database.

x. Butler, S.H. (2009). Motivational interviewing: a school counselors guide. M.S dissertation, Winona State University.

xi. Chike-Okoli, A and Ezeanolue, Uzoma (2016). Effective Teaching: Ensuring maximum Educational outcomes. Succeed and Prosper Books. ISBN - 978-2243-7-2

xii. Chike- Okoli, A (2018) "Attitudinal Change among Students: A Pathway to Success. Paper presented at the NewGate College of Health Technology 2017/ $20184^{\mathrm{TH}}$ Matriculation Ceremony held on Saturday, 25th November, 2017 at Minna, Niger State, Nigeria.

xiii. Chike-Okoli, A.; Okoli Success, C.; and Okoli Tochukwu, P. (2018) Effectiveness of Motivational Interviewing (MI) on The Academic Performance of low-academic Status Senior Secondary School Students in Niger State, Nigeria 5022. Article accepted for SKIREC publication-Journal of Management Research and Analysis. Vol. 9(6). ISBN 2394:2770 Impact factor 4.878

xiv. Conrado Joaquin Grimolizzi-Jensen (2015). Organizational Change: Evaluating the Effect of Motivational Interviewing in Readiness to Change. Walden University Scholar Works: Walden Dissertations and Doctoral Studies. http:/ / scholarworks.waldenu.edu/ dissertations.

xv. Covington, M., \& Mueller, K.J (2001) Instrinsic versus extrinsic motivation: an approach/ avoidance reformulation. Educational Psychology Review. 13.157-176. Retrieved June 16, 2008, from Eric database.

xvi. Daugherty, M. (2008). A randomized trail of motivational interviewing with college students for academic success. Unpublished doctoral dissertation, The University of New Mexico, USA.

xvii. Dilallo, J., Weis, G. (2009). Motivational interviewing and adolescent psychopharmacology. Journal of American academy of child adolescent psychology, 48.

xviii. Ferla, J, valcke, M, Cai, Y, (2009). Academic self-efficacy and academic self- concept: reconsidering structural relationships. Learning and individual differences, 19, 499-505.

xix. Flattum, C., Friend, S. Neumark-sztainer, D., Strong, M. (2009). Motivational interviewing as a component of schoolbased obesity prevention program for adolescent girls. Journal of the American dietetic association, 109, 91-94.

xx. Glynn, S. M. \& Koballa, T. R. (2006). Motivation to learn in college science. In J.J. Mintzes \& W. H. Leonard (Eds.), Handbook of college science teaching (pp. 25-32). Arlington, VA: National Science Teachers Association Press.

xxi. Glynn, S. M., Taasoobshirazi, G., \& Brickman, P. (2007). Non-science majors learning science: A theoretical model of motivation. Journal of Research in Science Teaching, 44(8), 1088-1107.

xxii. Janosz, M., Archambault, I., Morizot, J., \& Pagani, L. (2008). School engagement trajectories and their differential predictive relations to dropout. Journal of Social Issues, 64(1), 21-40.

xxiii. Jensen, C.D (2011). Effectiveness of Motivational Interviewing Interventions for Adolescent substance use Behavior change: A meta-analytic review.J Consult Clin Psych. 79(4). 433

xxiv. Kittles, M., \& Atkinson, C. (2009). The usefulness of motivational interviewing as a consultation and assessment tool for working with young people. Pastoral Care in Education, 27(3), 241-54.

xxv. Klose-McGarry, L. (2008). Understanding and fostering achievement motivation. Principal Leadership. Adapted from the handout "Fostering Achievement Motivation: information for parents and teachers" in Helping Children at Home and School III: information for parents and educators (in press), National Association of School Psychologists.

xxvi. Lawendowski, L. A. (1998). A motivational intervention for adolescent smokers. Preventive medicine, 24, 39.

xxvii. Miller, R.W., Rollnick, S. (2002). Motivational Interviewing: preparing people for change. New York: the Gilford press.

xxviii. Mojtaba Ashouri, Parvin Zolghadri, Mohammad Nehmati, Saber Alizadeh, and Ali Issazadegan. "The Effectiveness of Motivational Interview on Enhancing Self-Efficacy and Improving Self-Concept in Underdeveloped students". American Journal of Educational Research, vol. 3, no. 7 (2015): 923-928. Doi:10.12691/ education-3-7-17.

xxix. Odia, L.O. and Omofonmwan, S.I (2001). Declining Students Enrolment in Secondary School Geography. A case Study of Benin City. IRORO: Journal of Arts. 8(1\&2): 173-182

xxx. Odia, L.O. and Omofonmwan, S.I (2007). Educational System in Nigeria: Problems and Prospects. Journal of Social Sciences, 14(1): 81-86

xxxi. Ogunsaju S. (2004). A Guide to School Effectiveness in Nigeria. Ibadan, Laville Publications

xxxii. Omotere Tope (2013) Influence of School Environment on the Academic performance of Secondary School Students in Lagos State. Ego Booster Books www.omotere.tk no 45201316219

xxxiii. Otwell, S. P., \& Mullis, F. (1997). Academic achievement and counselor accountability. Elementary School Guidance \& Counseling, 31(4), 343-349.

xxxiv. Pajares, F., \& Urdan T. (2002). Academic motivation of adolescents. Greenwich, CT: Information Age Publishing. 
xxxv. Prochaska, J. O., \& Diclemente, C. C. (1982). Trans-theoretical theory: toward a more integrative model of change. Psychotherapy: theory, research and practice, 19, 276-282.

xxxvi. Uchefuna, M.C. (2001). A Study of Clinical Supervision and Teachers Effectiveness in Umuahia and Abia Educational Zones of Abia State. M.Ed Dissertation. Port-Harcourt, University of Port-Harcourt, Nigeria.

xxxvii. Wigfield, A., Lutz, L. S., \& Wagner, A. L. (2005). Early Adolescents development across the middle school years: implications for school counselors. Professional 